\title{
Deleterious Phases Precipitation on Superduplex Stainless Steel UNS S32750: Characterization by Light Optical and Scanning Electron Microscopy
}

\author{
Juan Manuel Pardal ${ }^{\mathrm{a}, *}$, Sérgio Souto Maior Tavares ${ }^{\mathrm{b}}$, Maria da Penha Cindra Fonseca $^{\mathrm{a}}$, \\ José Adailson de Souza ${ }^{\mathrm{a}}$, Lorena Menezes Vieira ${ }^{\mathrm{b}}$, Hamilton Ferreira Gomes de Abreu $^{\mathrm{c}}$
}

a Programa de Pós-graduação em Engenharia Mecânica, Universidade Federal Fluminense - UFF,

'Programa de Pós-graduação em Engenharia Química, Universidade Federal Fluminense - UFF,

Rua Passo da Pátria, 156, CEP 24210-240, Niterói, RJ, Brazil

${ }^{\mathrm{c}}$ Departamento de Engenharia Metalúrgica e de Materiais,

Universidade Federal do Ceará - UFC, Fortaleza, CE, Brazil

Received: April 6, 2010; Revised: August 26, 2010

\begin{abstract}
Deleterious phases precipitation in superduplex stainless steels is the main concern in fabrication by welding and hot forming of this class of material. Sigma, chi and secondary austenite phases are considered deleterious phases because they produce negative effects on corrosion resistance. Besides, sigma and chi phases also promote strong decrease of toughness. In the present work, the precipitations of sigma, chi and secondary austenite under aging in the $800-950{ }^{\circ} \mathrm{C}$ interval were studied in two UNS S32750 steels with different grain sizes. The deleterious phases could be quantified by light optical microscopy, with no distinction between them. Scanning electron microscopy was used to distinguish the individual phases in various aging conditions. The results elucidate the influence of the aging temperature and grain size on the kinetics precipitation and morphology of deleterious phases. The kinetics of deleterious phases is higher in the fine grained material in the initial stage of aging, but the maximum amount of deleterious phases is higher in the coarse grained steel.
\end{abstract}

Keywords: superduplex stainless steels, phase quantification, light optical microscopy, scanning electron microscopy

\section{Introduction}

Superduplex stainless steels (SDSS) are high strength and corrosion resistant materials used in the chemical and petrochemical industries. UNS S32750 steel has been applied in off-shore equipments used to store and process aggressive fluids ${ }^{1}$.

It is well known that the optimum mechanical and anti-corrosion properties of SDSS are obtained with equal proportions of ferrite $(\delta)$ and austenite $(\gamma)$ phases $^{2}$. The high pitting corrosion resistance is provided by high amounts of $\mathrm{Cr}$, Mo and $\mathrm{N}$ contents, which must be dissolved in the ferrite and austenite phases and not precipitated as deleterious compounds.

Sigma $(\sigma)$, chi $(\chi)$ and secondary austenite $\left(\gamma_{2}\right)$ phases, which may precipitate in SDSS during welding and hot forming processes, produce negative effects on corrosion resistance $e^{3-5}$. Besides, sigma and chi phases also promote strong embrittlement ${ }^{6,7}$. For these reasons, $\sigma$, $\chi$ and $\gamma_{2}$ are considered, among others, deleterious phases in SDSS.

Sigma and chi phases precipitate during re-heating in the $800-950{ }^{\circ} \mathrm{C}$ interval. However, $\chi$ is found to be formed in the first stages of aging. According to Michalska et al. ${ }^{8}$ and Chen et al. ${ }^{9}, \chi$ phase is metastable and undergoes the transformation $\chi \rightarrow \sigma$ under prolonged aging.

Sigma is the deleterious phase which may precipitate in higher amounts, generally assuming a lamellar morphology as a result of the ferritic eutectoid decomposition according to the reaction $\delta \rightarrow \sigma+\gamma_{2}$. However, at higher temperatures $\sigma$ may assume other morphologies ${ }^{9}$.

Secondary austenite $\left(\gamma_{2}\right)$ phase may also be independently formed by diffusion at high temperatures. One of the characteristics of this phase is the low nitrogen content, which leads to a poor corrosion resistance when compared to the austenite $(\gamma)$ previously formed in the solution heat treatment ${ }^{10}$. Chen et al. ${ }^{9}$ observed plates of $\sigma$ phase associated with $\gamma_{2}$ in the ferrite boundaries. However, $\gamma_{2}$ may also grow from the primary $\gamma$ toward the ferritic domains, or by heterogeneous nucleation in the intergranular chromium nitride $\left(\mathrm{Cr}_{2} \mathrm{~N}\right)$ particles ${ }^{11}$.
In duplex and superduplex stainless steels intense $\mathrm{Cr}_{2} \mathrm{~N}$ precipitation occurs when the material is ferritized at high temperatures and rapidly cooled. This is typically found in heat affected zones of welded joints ${ }^{12}$.

Thus, the present work aims at studying the kinetics precipitation of the deleterious phases $\sigma, \chi$, and $\gamma_{2}$ which occurs at almost the same temperature range. Scanning electron microscopy was used to distinguish the three phases and to better understand the evolution of each phase. The study was conducted in two SDSS of the same grade but different grain sizes.

\section{Experimental}

Two superduplex steels, named as "SD-A" and "SD-B" in this work, with chemical compositions shown in Table 1, were studied. Both materials were previously solution treated by the purchaser. However, steel SD-A presents much finer ferritic and austenitic grain sizes than steel SD-B, which will be shown later. Samples of $15 \times 10 \times 5 \mathrm{~mm}$ were cut and heat treated at 800,850, 900 and $950{ }^{\circ} \mathrm{C}$ by $5,15,30,45,60,90,120$ and 240 minutes, followed by water cooling. Microstructures analysis were carried out in a light optical microscope (LOM) NEOPHOT 32 and in a scanning electron microscopy (SEM) JEOL 6460LV with microanalysis by energy dispersive spectroscopy (EDS). Table 2 shows the list of metallographic etches used and the objective of each one. Some samples were observed without etch in the SEM, using the backscattered mode. Electron beam energy used in the EDS analysis was $20 \mathrm{kV}$.

Deleterious phases revealed by electrochemical etching with $\mathrm{KOH}$ solution were quantified by image analysis using Image Tools software $^{13}$, analyzing 20 fields per condition with $240 \times, 475 \times$ and $950 \times$. 
Table 1. Chemical compositions of the materials studied.

\begin{tabular}{ccccccccccccc}
\hline \multirow{2}{*}{ Material } & \multicolumn{10}{c}{ wt. $(\%)(\% \mathrm{Fe}=$ balance $)$} \\
\cline { 2 - 13 } & $\mathrm{Cr}$ & $\mathrm{Ni}$ & $\mathrm{Mo}$ & $\mathrm{Mn}$ & $\mathrm{Si}$ & $\mathrm{N}$ & $\mathrm{Cu}$ & $\mathrm{W}$ & $\mathrm{C}$ & $\mathrm{P}$ & $\mathrm{S}$ \\
\hline SD-A & 24.57 & 6.68 & 3.75 & 0.83 & 0.34 & 0.28 & 0.25 & - & 0.02 & 0.026 & 0.000 \\
SD-B & 24.80 & 6.75 & 3.79 & 0.78 & 0.54 & 0.27 & 0.10 & 0.04 & 0.019 & 0.026 & 0.001 \\
\hline
\end{tabular}

Table 2. Reagents employed to reveal microstructural characteristics in a SDSS.

\begin{tabular}{cc}
\hline Reagent & Composition - Procedure \\
\hline Beraha & $20 \mathrm{~mL} \mathrm{HCl}+100 \mathrm{~mL} \mathrm{H}_{2} \mathrm{O}+0.3$ to $0.6 \mathrm{~g}$ of potassium metabissulfite. \\
Use hot $\left(40-60{ }^{\circ} \mathrm{C}\right)$ & Reveal ferrite and austenite ${ }^{14}$ \\
Potassium hydroxide & $15 \mathrm{~g} \mathrm{KOH}+100 \mathrm{~mL} \mathrm{de} \mathrm{H}_{2} \mathrm{O}-$ Electrolytic etching: $3 \mathrm{~V}-12$ seconds \\
\hline
\end{tabular}

\section{Results and Discussion}

\subsection{Light Optical Microscope (LOM) analysis}

Figures $1 \mathrm{a}$ and $\mathrm{b}$ show the microstructures in the as received condition of materials SD-A and SD-B, respectively. These images were obtained with Beraha's etching which provides a very good contrast between ferrite and austenite phases, but does not reveal grain boundaries. However, it is clear that material SD-A presents a much finer microstructure than material SD-B. The best measurements of the grain sizes of ferrite and austenite phases were achieved by electron backscattered scanning diffraction (EBSD) analysis, whose details are explained in another work ${ }^{16}$. Table 3 summarizes the grain sizes and phase amounts of each material in the as received condition.

Figures 2a-f show the microstructural evolution of images obtained by LOM with $\mathrm{KOH}$ etch in samples of both materials aged at $800{ }^{\circ} \mathrm{C}$. The dark phases were quantified and computed as "deleterious phases". These dark regions include $\sigma$ and $\chi$ phases and the $\gamma_{2}$ formed by eutectoid decomposition. Figures 3 and 4 show the evolution of the deleterious phases with time for the four investigated temperatures. The kinetics precipitation in the fine grained material SD-A is clearly faster than in material SD-B at the initial stages, which means that the grain refinement promotes a shorter incubation time and higher nucleation rate of deleterious phases ${ }^{16}$.

The precipitation curves of Figures 3 and 4 show a saturation value for the amount of deleterious phases. This saturation value decreases with aging temperature as shown in Figure 5. It is interesting to note that, despite the faster initial kinetics of precipitation, the fine grain material "SD-A" present lower saturation values than SD-B in all temperatures. Figures $6 \mathrm{a}$ and $\mathrm{b}$ show the microstructures of specimens treated at $850^{\circ} \mathrm{C}$ by 240 minutes. At this heat treatment condition, material SD-A show many $\gamma_{2}$ large particles precipitated inside the ferrite domains, while SD-B shows a higher proportion of fine deleterious phases originated from the $\delta$ eutectoid decomposition, as delimitated by a circle in Figure $6 \mathrm{~b}$. The higher amount and size of independent $\gamma_{2}$ phase in material SD-A can be attributed to its higher grain boundaries areas available to the $\delta \rightarrow \gamma_{2}$ transformation. Although the $\gamma_{2}$ particles precipitated at the ferrite grain boundaries can create $\mathrm{Cr}$ and Mo-rich regions and accelerate the $\chi$ and $\sigma$ phases formation in the beginning, in a further step they act as barriers, just like an impingement effect. This explains the lower saturation values achieved in material SD-A. Figures $7 \mathrm{a}$ and $\mathrm{b}$ and Figures $8 \mathrm{a}$ and $\mathrm{b}$ show this barrier effect of $\gamma_{2}$ in specimens aged at 900 and $950{ }^{\circ} \mathrm{C}$ for 240 minutes, respectively.

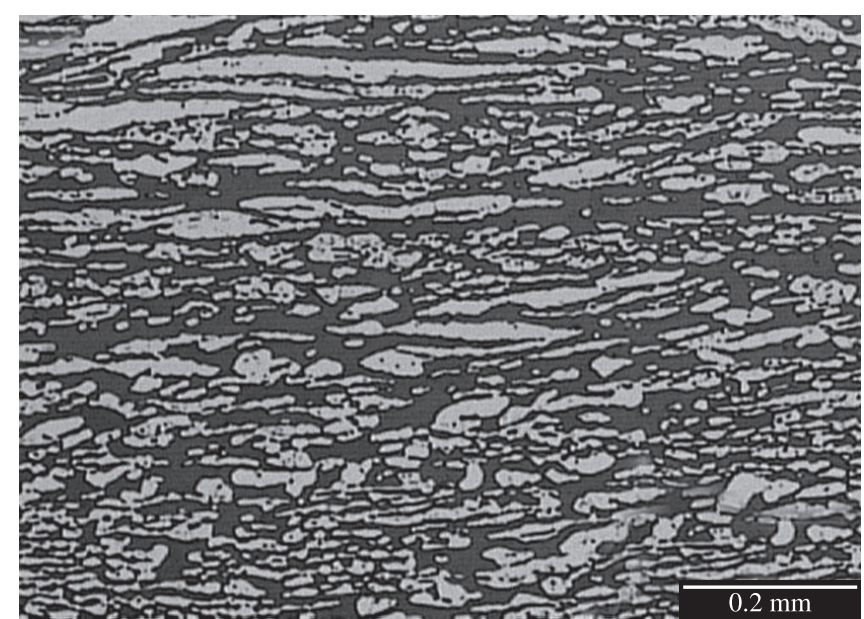

(a)

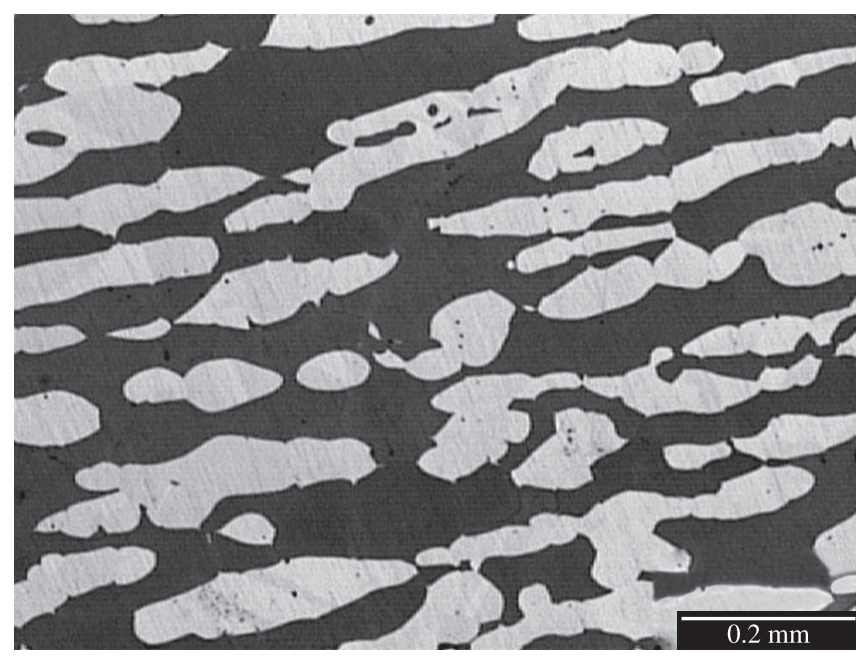

(b)

Figure 1. As received materials etched with Beraha's reagent: a) SD-A; and b) SD-B.

\subsection{Scanning Electron Microscopy (SEM) analysis}

Figure 9 shows the deleterious phases observed in detail by backscattered electron image in the specimen treated at $900{ }^{\circ} \mathrm{C}$ by 240 minutes. This image was obtained in a specimen polished but not etched. Points 1, 2 and 3 were analyzed by EDS and identified as $\chi, \sigma$ 
Table 3. Percentages of phases and grain sizes in materials SDA and SDB as received.

\begin{tabular}{|c|c|c|c|c|c|c|}
\hline \multirow{3}{*}{ Material } & \multicolumn{3}{|c|}{ Ferrite $(\delta)$} & \multicolumn{3}{|c|}{ Austenite $(\gamma)$} \\
\hline & \multirow{2}{*}{$\begin{array}{c}\text { Amount } \\
(\%)\end{array}$} & \multicolumn{2}{|c|}{ Grain size } & \multirow{2}{*}{$\begin{array}{c}\text { Amount } \\
(\%)\end{array}$} & \multicolumn{2}{|c|}{ Grain size } \\
\hline & & $\mu \mathrm{m}$ & $\operatorname{ASTM~n}^{\circ}$ & & $\mu \mathrm{m}$ & $\operatorname{ASTM~n}^{\circ}$ \\
\hline SD-A & 55.05 & 29.42 & 7.2 & 44.95 & 24.75 & 7.7 \\
\hline SD-B & 49.95 & 132.36 & 2.8 & 50.05 & 138.32 & 2.7 \\
\hline
\end{tabular}

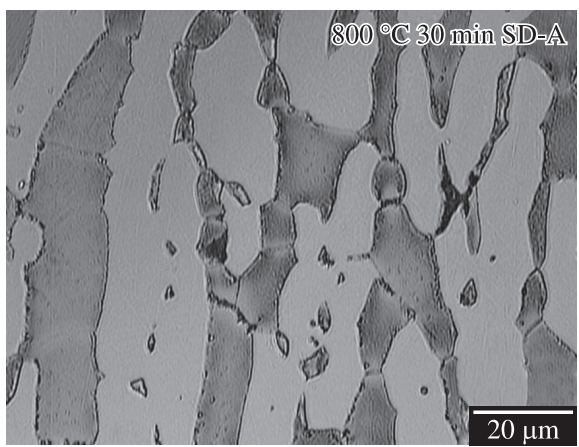

(a)

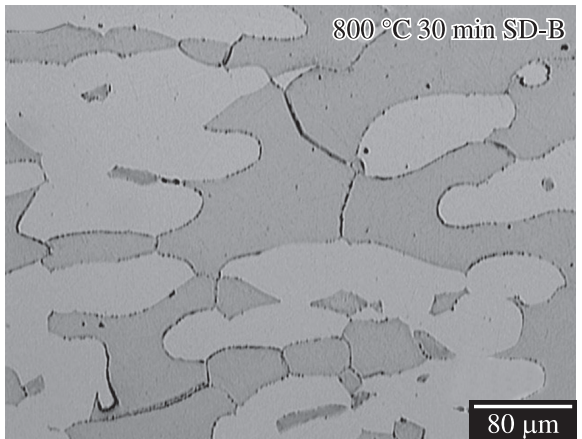

(d)

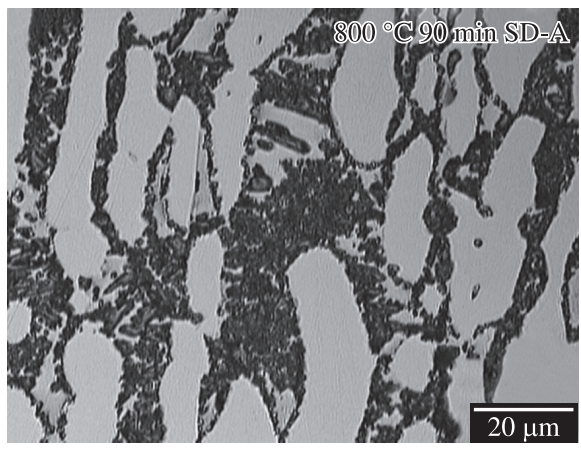

(b)

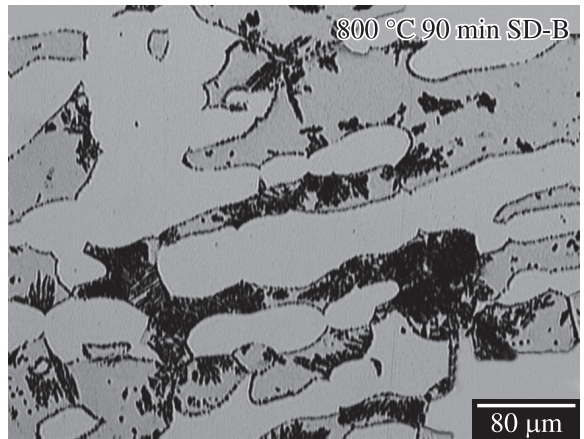

(e)

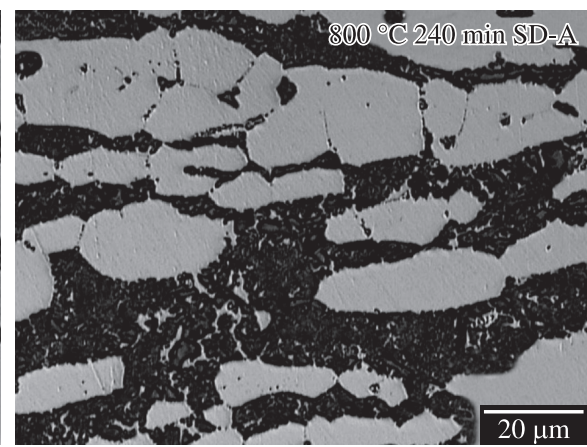

(c)

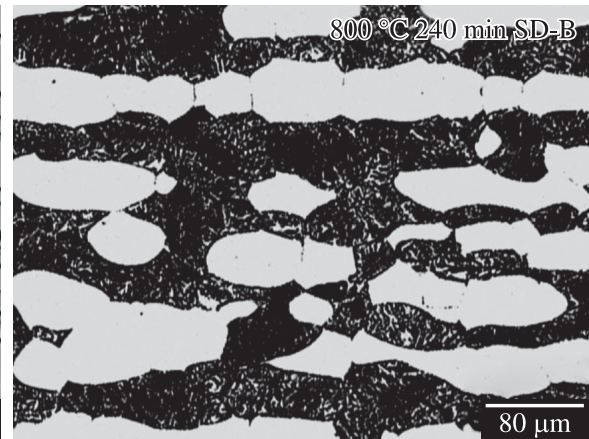

(f)

Figure 2. Evolution microestructural images obtained by LOM in aged conditions at $800{ }^{\circ} \mathrm{C}$ for a SD-A and SD-B, respectively.

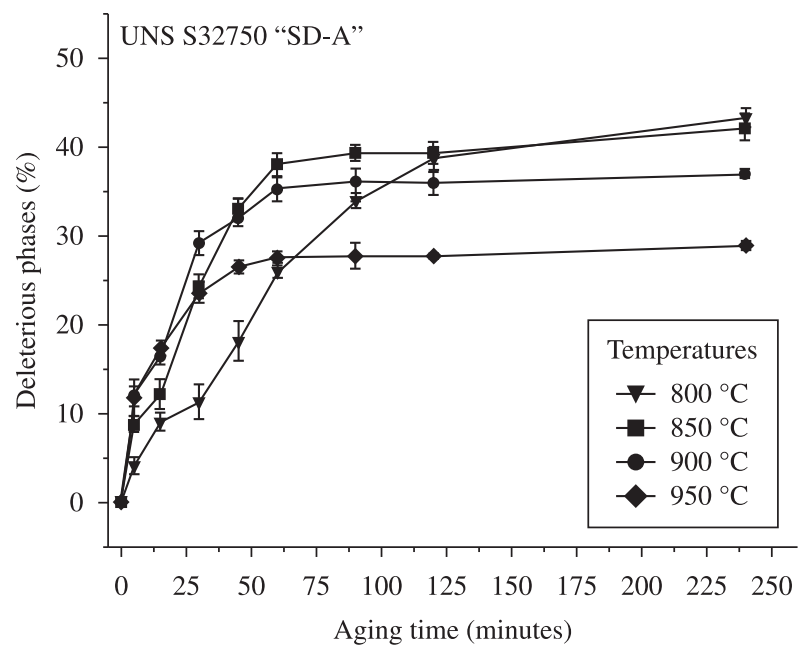

Figure 3. Percentage of deleterious phases precipitates against aging time at $800,850,900$ and $950{ }^{\circ} \mathrm{C}$ for SD-A.

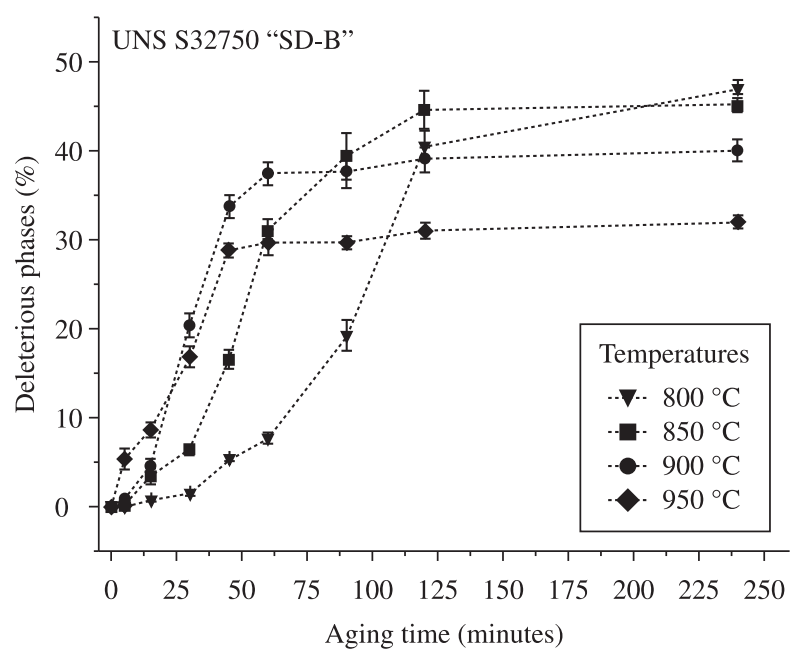

Figure 4. Percentage of deleterious phases precipitates against aging time at $800,850,900$ and $950{ }^{\circ} \mathrm{C}$ for SD-B. 


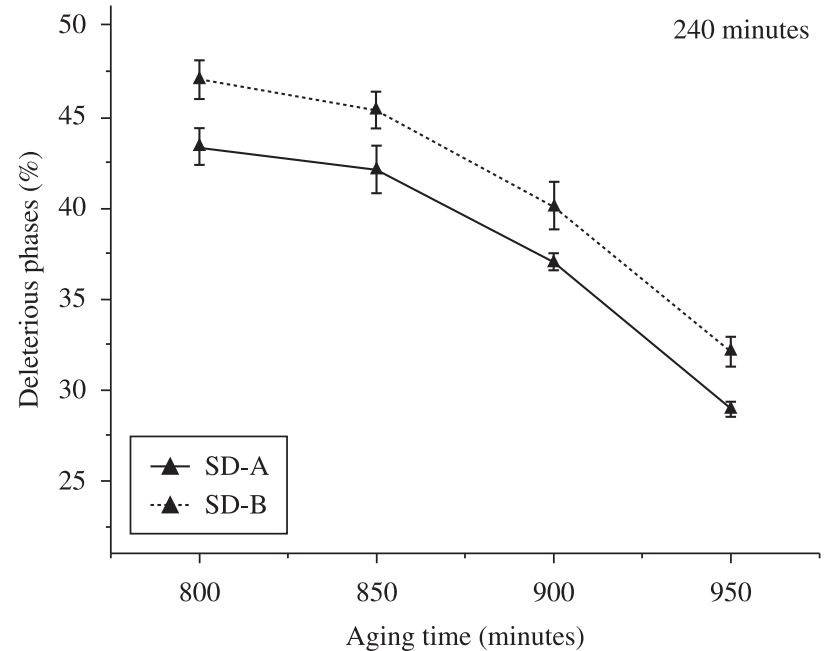

Figure 5. Saturation value of deleterious phases as function of aging temperature in SD-A and SD-B. and $\gamma_{2}$ phases, respectively. Table 4 shows the chemical compositions of each phase. Although these results are rather qualitative than quantitative, due to the small size of the particles analyzed, they are important to identify the different phases. Phase $\chi$ has the highest Mo content and, as a consequence, corresponds to the lightest regions in the image. Figure 10a and b show the SEM images of samples in the early stages of aging $\left(850{ }^{\circ} \mathrm{C} / 15\right.$ minutes), in which $\chi$ phase in the $\gamma / \delta$ and $\delta / \delta$ boundaries were mainly observed. In Figure 9 , a very small amount of phase $\chi$ is present, which is in accordance with its metastable feature, as observed by Michalska et al. ${ }^{8}$ and Chen et al..

Table 4. EDS analysis of deleterious phases obtained in Figure 9.

\begin{tabular}{ccccccc}
\hline \multirow{2}{*}{$\begin{array}{c}\text { Analyzed } \\
\text { Point }\end{array}$} & \multicolumn{5}{c}{ Chemical composition (wt. (\%)) } & \multirow{2}{*}{ Phase } \\
\cline { 2 - 6 } & $\mathrm{Fe}$ & $\mathrm{Cr}$ & $\mathrm{Ni}$ & \multicolumn{1}{c}{$\mathrm{Mo}$} & $\mathrm{Si}$ & \\
\hline 1 & 54.10 & 26.20 & 3.56 & 15.22 & 0.94 & $\chi$ \\
2 & 56.36 & 32.13 & 3.84 & 6.85 & 0.83 & $\sigma$ \\
3 & 69.49 & 22.14 & 6.70 & 1.29 & 0.39 & $\gamma 2$ \\
\hline
\end{tabular}

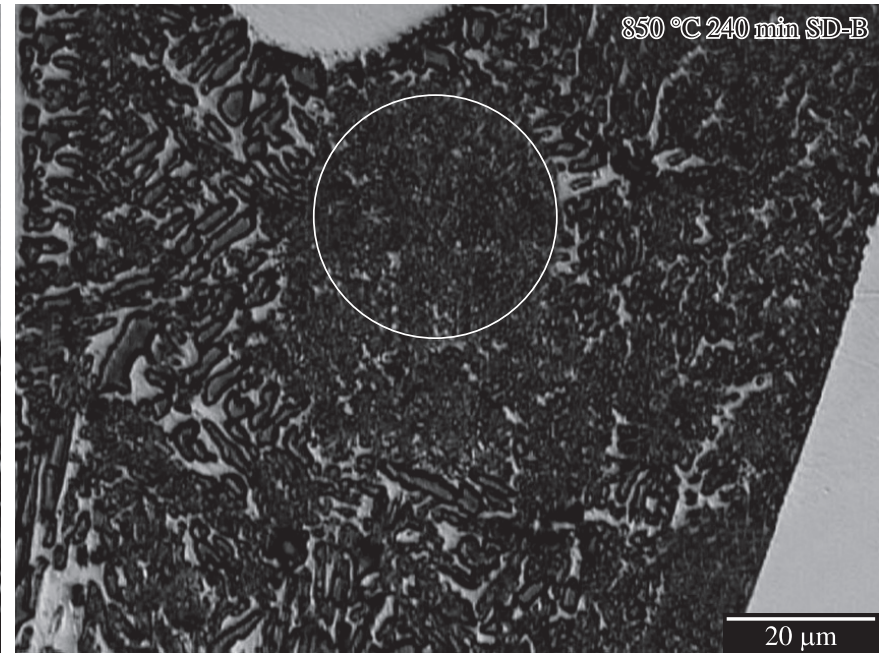

(b)

Figure 6. LOM images from samples treated at $850{ }^{\circ} \mathrm{C}$ for 240 minutes: a) SD-A; and b) SD-B
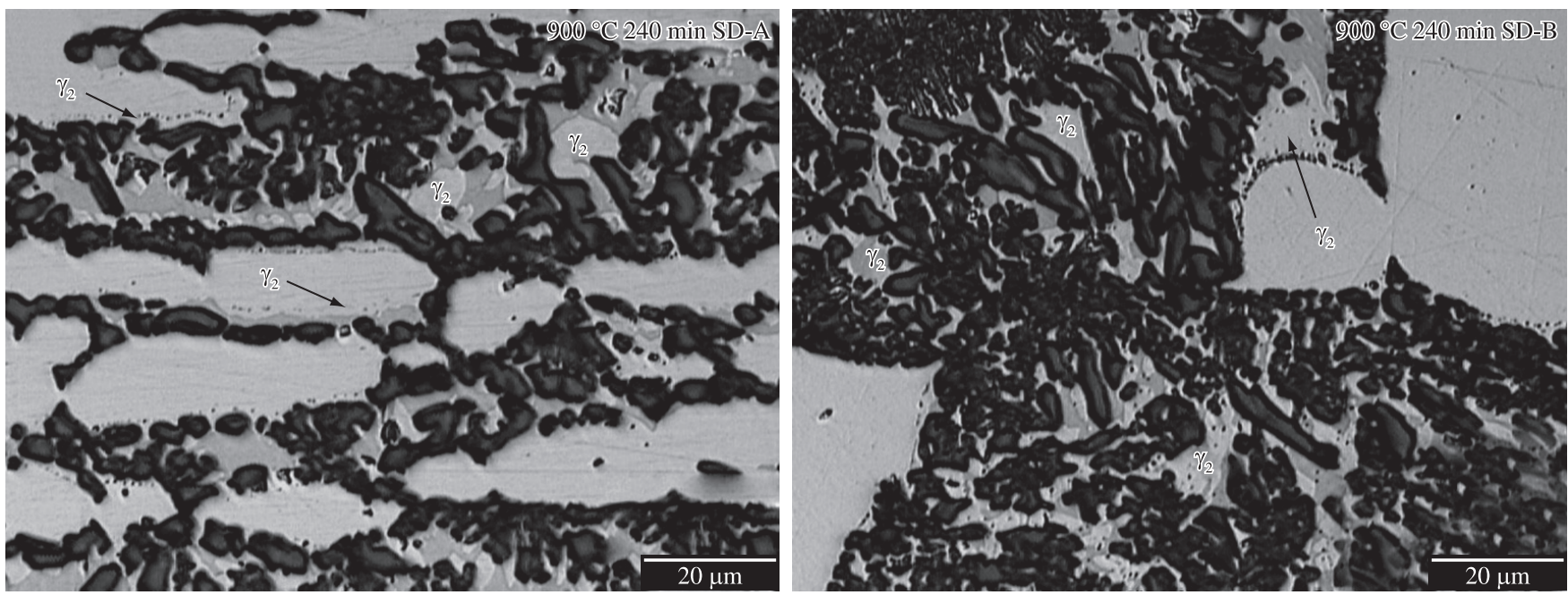

Figure 7. LOM images from samples treated at $900{ }^{\circ} \mathrm{C}$ for 240 minutes: a) SD-A; and b) SD-B. 


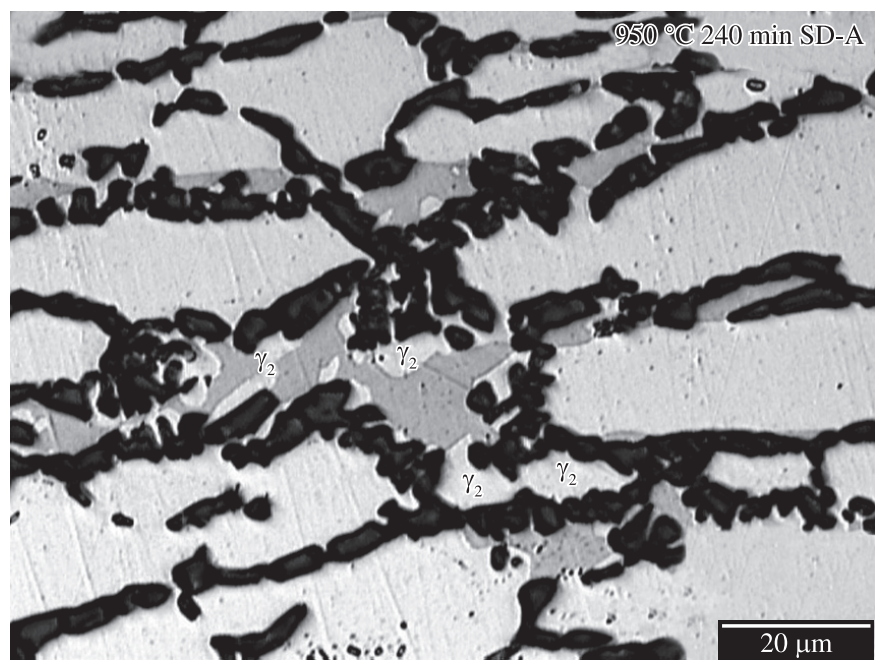

(a)

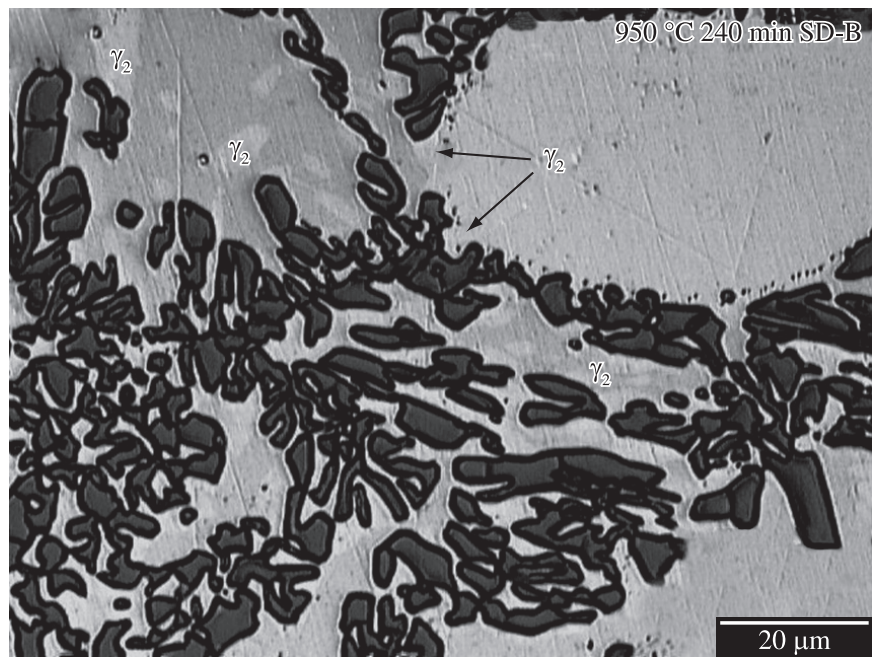

(b)

Figure 8. LOM images from samples treated at $950{ }^{\circ} \mathrm{C}$ for 240 minutes: a) SD-A and b) SD-B.

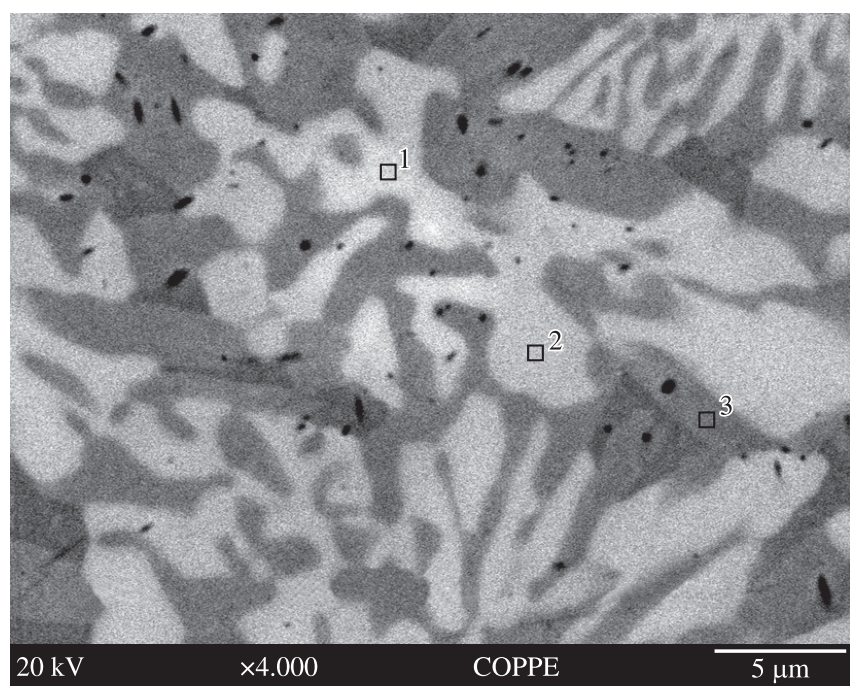

Figure 9. SEM image from sample treated at $900{ }^{\circ} \mathrm{C}$ for 240 minutes in a SD-B.

Figure 9 also shows $\sigma$ and $\gamma_{2}$ phases. At this condition only small remaining ferrite is present, since this phase was almost completely transformed. EDS results show that $\gamma_{2}$ particles contain very small Mo and $\mathrm{Cr}$ contents. According to Lippold and Kotecki ${ }^{10}$, these $\gamma_{2}$ particles formed at low temperatures are also nitrogen depleted. These chemical composition features makes $\gamma_{2}$ particles very susceptible to pitting corrosion and to wear by grinding and polishing. The small black points mainly concentrated in the $\gamma_{2}$ observed in Figure 9, may be attributed to pitting and/or pulling by wear during the sample preparation.

Figure $11 \mathrm{a}$ and $\mathrm{b}$ show the images of the specimens of materials SD-A and SD-B aged at $900{ }^{\circ} \mathrm{C}$ for 60 minutes, for comparison. Table 5 shows the EDS analysis from points 1, 2, 3, 4 and 5 of Figure 11a. The following features must be highlighted based on these figures:

- Typical eutectoid $\gamma_{2}+\sigma$ structure are observed in Figure $11 \mathrm{~b}$ from SD-B.

- A third form of $\gamma_{2}$ is observed, that results from the growth of pre-existing $\gamma$ phase. This is more evident in Figure $11 \mathrm{~b}$, where small pits and/or chromium carbides are also observed in the $\gamma_{2}$ layer adjacent to the $\gamma$ island. The nature of these small black points could not be clarified by SEM. The hypothesis of carbide

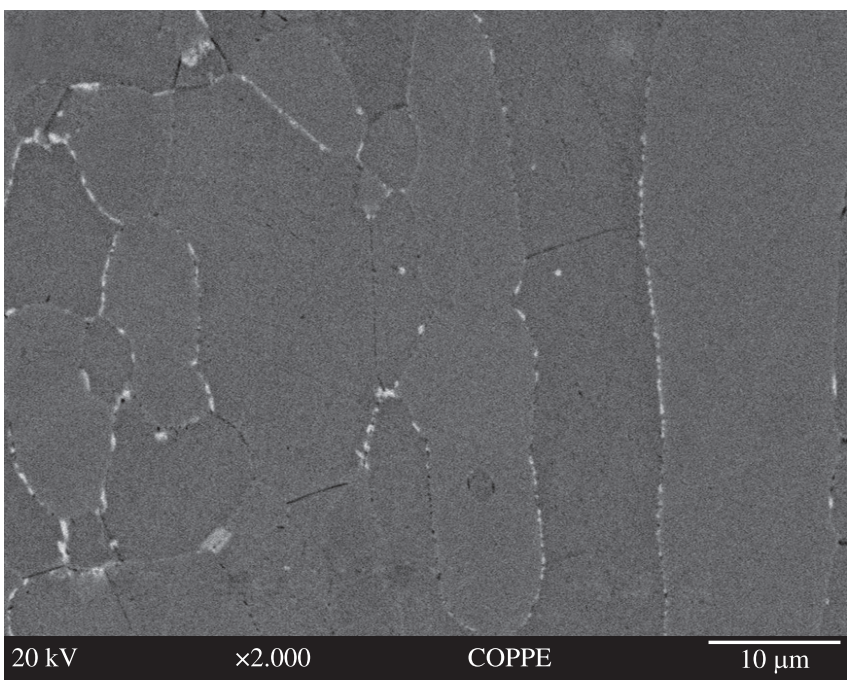

(a)

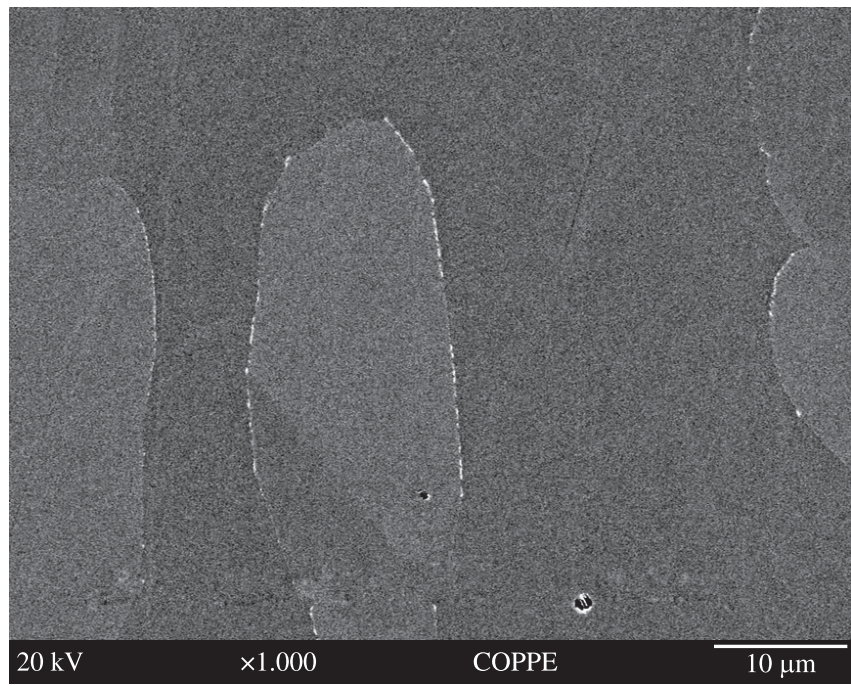

(b)

Figure 10. SEM images from samples treated at $850{ }^{\circ} \mathrm{C}$ for 15 minutes: a) $\mathrm{SD}-\mathrm{A}$; and b) SD-B. 


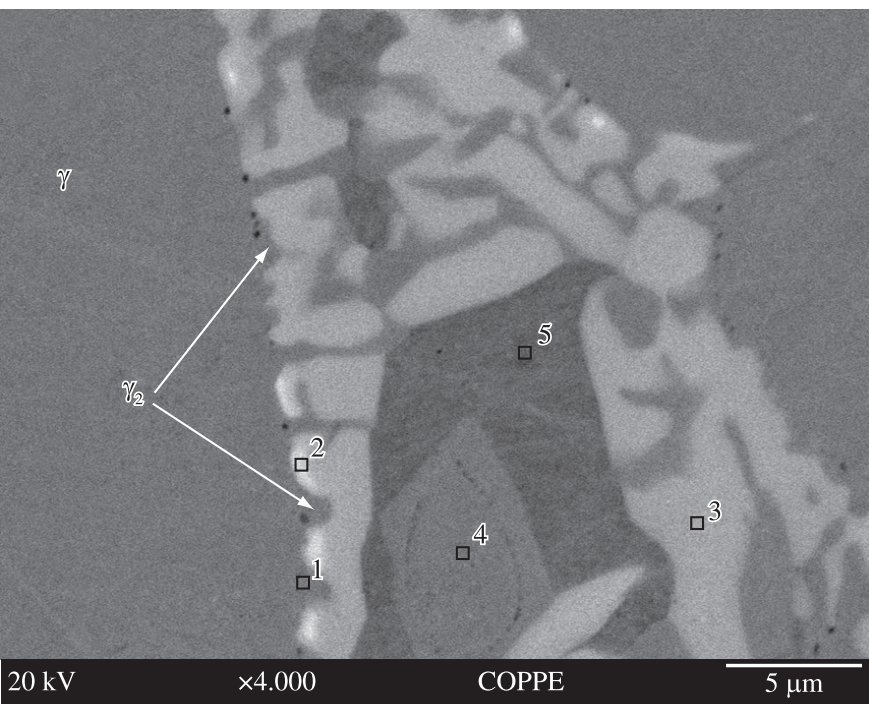

(a)

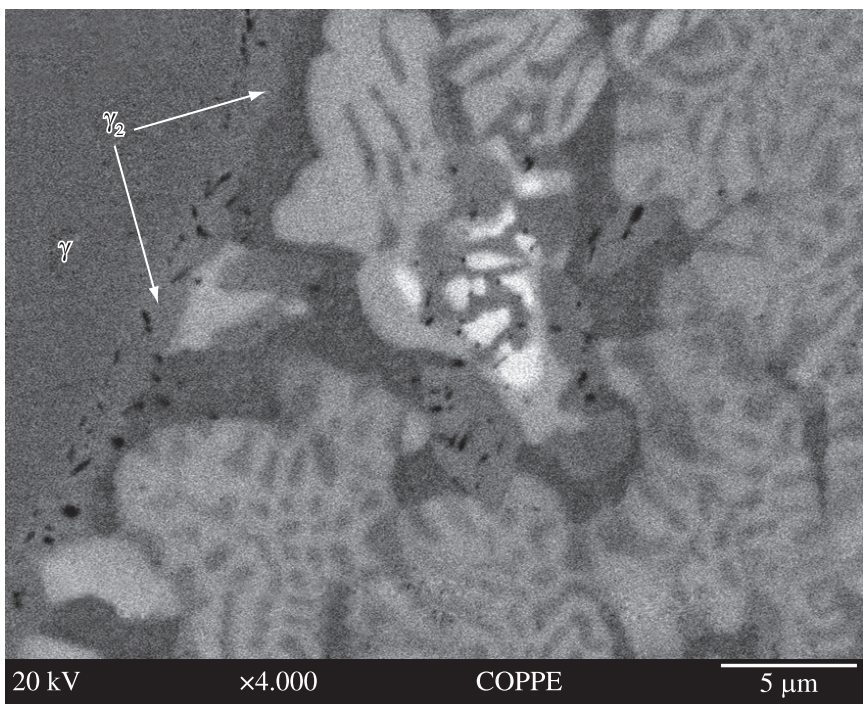

(b)

Figure 11. SEM images from samples treated at $900{ }^{\circ} \mathrm{C}$ for 60 minutes: a) SD-A; and b) SD-B.

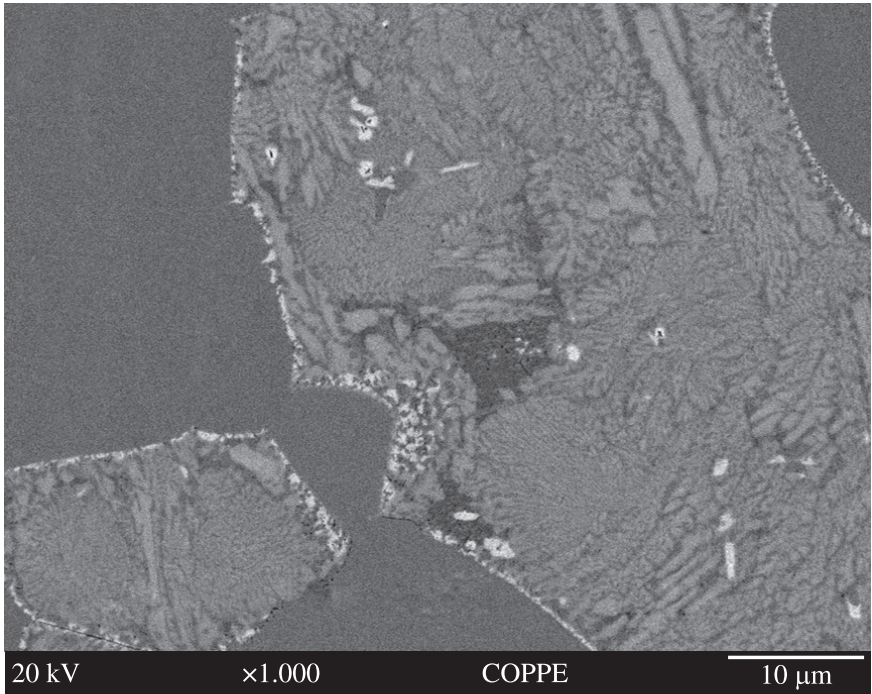

(a)

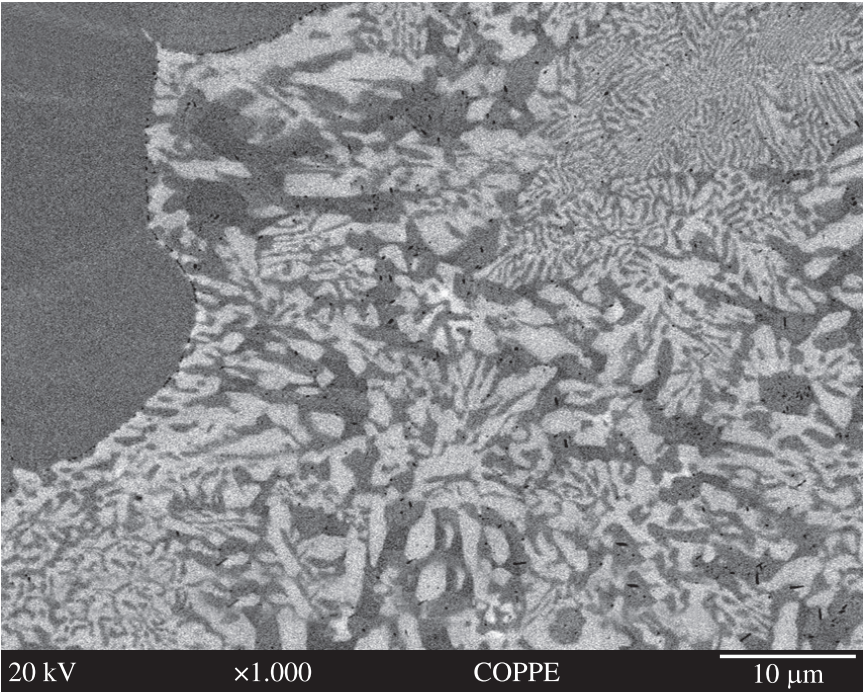

(b)

Figure 12. SEM images from SD-B samples treated at $800{ }^{\circ} \mathrm{C}$ for 240 minutes and $900{ }^{\circ} \mathrm{C}$ for 240 minutes, respectively.

Table 5. EDS analysis of deleterious phases obtained in Figure 11a.

\begin{tabular}{ccccccc}
\hline \multirow{2}{*}{$\begin{array}{c}\text { Analyzed } \\
\text { Point }\end{array}$} & \multicolumn{5}{c}{ Chemical composition (wt. (\%)) } & \multirow{2}{*}{ Phase } \\
\cline { 2 - 5 } & $\mathrm{Fe}$ & $\mathrm{Cr}$ & $\mathrm{Ni}$ & $\mathrm{Mo}$ & $\mathrm{Si}$ & \\
\hline 1 & 64.86 & 23.98 & 8.15 & 2.57 & 0.42 & $\gamma$ \\
2 & 56.01 & 29.31 & 3.97 & 10.12 & 0.60 & $\chi$ \\
3 & 57.44 & 31.77 & 3.63 & 6.54 & 0.61 & $\sigma$ \\
4 & 64.35 & 24.45 & 8.16 & 2.57 & 0.47 & $\gamma_{2}$ \\
5 & 67.23 & 27.15 & 3.46 & 1.73 & 0.44 & $\delta$ \\
\hline
\end{tabular}

precipitation by $\delta \rightarrow \gamma_{2}+\mathrm{M}_{23} \mathrm{C}_{6}$ is considered after the work of Lee et al. ${ }^{17}$. On the other hand, this form of $\gamma_{2}$ precipitation is also clearly seen in LOM images in the Figures 7a-b and $8 \mathrm{~b}$.

- Point 4 in Figure 11a corresponds to a $\gamma_{2}$ plate which has been formed independently. Its chemical composition (Table 5) contains more Mo and $\mathrm{Cr}$ than the $\gamma_{2}$ formed by eutectoid decomposition observed in Figure 9 (Table 4).

- $\sigma$ and $\gamma_{2}$ phases observed in SD-B are much finer than in SDA. The fact that by reducing grain size the $\sigma$ particles become coarser may be explained by the higher solute diffusivity in the fine grained material. Figures $12 \mathrm{a}$ and $\mathrm{b}$ from material SD-B aged for 240 minutes at 800 and $900{ }^{\circ} \mathrm{C}$ show that the increase of aging temperature also promotes the coarsening of $\sigma$ particles. 


\section{Conclusions}

The precipitation of deleterious phases $\sigma, \chi$ and $\gamma_{2}$ during isothermal aging at $800,850,900$ and $950{ }^{\circ} \mathrm{C}$ were investigated by light optical microscopy (LOM) and scanning electron microscopy (SEM). Based on the results, the following conclusions may be highlighted:

1. Three mechanisms of $\gamma_{2}$ precipitation were observed: eutectoid decomposition $(\delta \rightarrow \gamma+\sigma)$, independent precipitation and growth of $\gamma_{2}$ plates, and growing of pre-existing $\gamma$ phase islands.

2 . The initial stage of aging at $850{ }^{\circ} \mathrm{C}$ is characterized by the precipitation of Mo-rich phase at the $\gamma / \delta$ and $\delta / \delta$ boundaries. The increase of aging time promotes the replacement of the metastable $\chi$ phase by $\sigma$.

3. The deleterious phases $\sigma, \chi$ and $\gamma_{2}$ formed by eutectoid reaction were quantified by LOM in samples prepared by electrolytic etching in $\mathrm{KOH}$ solution (3V, 12 seconds). Curves of deleterious phases against aging time were presented. These curves present a saturation value of the deleterious phase amounts for long aging times. The saturation value is found to be lower in the fine grained steel, which is attributed to the higher grain boundaries areas available to the $\delta \rightarrow \gamma_{2}$ transformation.

4. Since deleterious phase precipitation starts in the grain boundaries, the fine grained material presents a faster kinetic precipitation in the initial stages. However, the independent $\gamma_{2}$ particles precipitation is more pronounced in the fine grained material. These $\gamma_{2}$ particles act as barriers to $\sigma$ precipitation in advanced stages of aging. As consequence, the saturation value is found to be higher in the coarse grained steel. The increase of aging temperature also intensifies the independent $\gamma_{2}$ precipitation and then decreases the saturation value.

5. $\gamma_{2}$ precipitated by eutectoid reaction has very low pitting resistance because of its low $\mathrm{Cr}$ and Mo contents.

6 . The $\sigma$ and $\gamma_{2}$ particles are coarser in the fine grained than in the coarse grained steel. The increase of aging temperature also promotes the coarsening of these particles due to the increase of solute atoms diffusivities.

\section{Acknowledgements}

The authors acknowledge the Brazilian research agencies (CAPES, FAPERJ and CNPq) for financial support.

\section{References}

1. Reick W, Pohl M and Padilha AF. O desenvolvimento dos aços inoxidáveis ferríticos-austeníticos com microestrutura duplex. Metalurgia e Materiais. 1992; 48:551.
2. Muthupandi V, Srinivasan PB, Seshadri SK and Sundaresan S. Effect of weld metal chemistry and heat input on the structure and properties of duplex stainless steel welds. Materials Science and Engeneering A. 2003; 358:9.

3. Potgieter JH. Influence of $\sigma$ phase on general and pitting corrosion resistance of SAF 2205 duplex stainless steel. British Corrosion Journal. 1992; 27(3):219.

4. Lopez N, Cid M and Puiggali M. Influence of $\sigma$-phase on mechanical properties and corrosion resistance of duplex stainless steels. Corrosion Science. 1999; 41:1615.

5. Domínguez-Aguilar MA and Newman RC. Detection of deleterious phases in duplex stainless steel by weak galvanostatic polarization in alkaline solution. Corrosion Science. 2006; 48:2560.

6. Nilsson JO, Kangas P, Karlsson T and Wilson A. Mechanical properties, microstructural stability and kinetics of phase formation in $29 \mathrm{Cr}-6 \mathrm{Ni}$ 2Mo-0,38N superduplex stainless steel. Metallurgical and Materials Transactions A. 2000; 31A:35.

7. Tavares SSM, Silva MR and Neto JM. Magnetic property changes during embrittlement of a duplex stainless steel. Journal of Alloys and Compounds. 2000; 313:168.

8. Michalska J and Sozanska M. qualitative and quantitative analysis of e phases in 2205 duplex stainless steel. Materials Characterization. 2006; $56: 355$.

9. Chen TH, Weng KL and Yang JR. The effect of high-temperature exposure on the microstructural stability and toughness property in a 2205 duplex stainless steel. Materials Science and Engeneering A. 2002; A338:259.

10. Lippold JC and Kotecki DJ. welding metallurgy and weldability of stainless steels. John Wiley \& Sons, 2005.

11. Ramirez AJ, Lippold JC and Brandi SD. The relationship between chromium nitride and secondary austenite precipitation in duplex stainless steels. Metallurgical and Materials Transactions A. 2003; 34A:1575.

12. Nilsson JO. Overview super duplex stainless steels. Materials Science and Technology. 1992; 8:685.

13. University of Texas Health Science Center. Image Tool. Version 3.0. San Antonio. Free software.

14. ASM International. Metals Handbook Volume 09 - Metallography and Microstructures, 2004. p. 2733. CD-ROM.

15. Park CJ, Kwon HS \& Lohrengel MM. Micro-electrochemical polarization study on $25 \%$ cr duplex stainless steel. Materials Science and Engeneering A. 2004; A372:180.

16. Pardal JM, Tavares SSM, Cindra Fonseca MP, Souza JA, Corte RRA and Abreu HFG. Influence of the grain size on deleterious phase precipitation in superduplex stainless steel UNS S32750. Materials Characterization. 2009; 60:165.

17. Lee KM, Cho HS and Choi DC. Effect of isothermal treatment of saf 2205 duplex stainless steel on migration of $\delta / \gamma$ interface boundary and growth of austenite. Journal of Alloys and Compounds. 1999; 285:156. 
